Vol. 1, No. 3, pp. 1-6, 2020

\title{
Application of Linear Programming in Oil Production Distribution Networks: Literature Review
}

\author{
Yasir Salih $^{1 *}$, Hani Rubiani ${ }^{2}$ \\ ${ }^{I}$ Department of Mathematics, Faculty of Education, Red Sea University, SUDAN \\ ${ }^{2}$ Department of Electrical Engineering, Universitas Muhammadiyah Tasikmalaya, INDONESIA \\ *Corresponding author e-mail address: yasirsalih2015@gmail.com
}

\begin{abstract}
In the oil production distribution network, there are three main nodes, namely the supply node, the transshipment node, and the demand node. The pattern of distribution of oil production from the supply node to the demand node is very diverse and can affect the costs to be incurred. Therefore, a company must be able to determine the right distribution pattern, so that the costs incurred are optimal. This paper intends to conduct a study of how to determine and calculate the distribution patterns and the minimum total costs incurred, using the primal-dual linear program method. Based on the results of the case analysis, it is known that the number of supply commodities will be the same as the number of demand commodities, but the distribution from each source does not necessarily have the same capacity and costs. Therefore, the distribution pattern is determined based on the existing cost and capacity, so that cost optimization can be achieved.
\end{abstract}

Keywords: Oil production, supply node, transshipment node, demand node, costs optimal.

\section{Introduction}

The word production is used by economists to describe the making of goods and services that have economic value. For economists, the production of goods and services must go through stages, which include design, manufacture, transportation, warehousing, sales, and marketing (Iheagwara et al., 2014). The entire logistics system that converts raw materials and primary resources into an end item that is ready to be used (consumed) to meet the needs of consumers (Ezema \& Amakom, 2012).

One example of this kind is the logistics system in the oil industry. Crude oil is obtained from a variety of oil fields, where each field consists of several crude-producing wells that have various chemical compositions. Crude oil is channeled through pipes which are sometimes very broad and complicated, whereas to separate oil and gas is done by channeling oil to oil refineries and gas flow is channeled to gas factories. Gas plants refine methane, sulfur, and natural gas liquids (Thompson \& Thore, 1992). 
The entire network from oil wells to consumers stretches to almost half the globe. Therefore, this kind of production process has many complex interrelated constraints with various factors, so it requires careful planning (Turkay, 1998; Boo et al., 2013). One factor is cost, this kind of production requires a very large cost. Therefore, production actors must be able to obtain optimal costs but the demand for final goods and services does not disappoint consumers (Antunes \& Gomes, 2008).

In the process of oil production, the production actors must obtain optimal costs. This optimal cost can be obtained using a method, namely the operational research method. Operational research is a method that deals with optimal decision making in systems, and the preparation of models of systems, both deterministic and probabilistic, that originate from real problems (Dragićević \& Bojić, 2009; 2010).

One method of operations research is linear programming. Using this programming an oil production and transportation problem can be made into a mathematical model and an optimal solution can be obtained, namely obtaining a minimum total cost. Therefore, in this paper, a primal-dual linear program is used, and to simplify the calculation a program is used in a linear program, namely POM.

\section{Oil Production Distribution Network Model}

The distribution network of oil production has its characteristics so that in that network a pure network model can be formed. In general, the pure network model of oil production distribution can be seen in Figure 1.

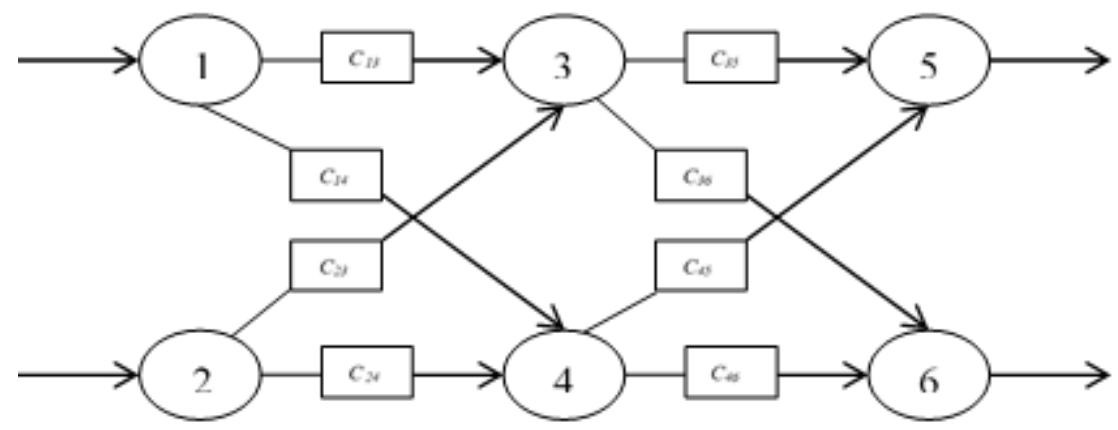

Figure 1: Pure Network Model of Oil Distribution

In Figure 1, it can be seen that a single homogeneous commodity is channeled through the network. These networks consist of nodes and direct paths that connect a pair of nodes. Each node can be a net supply node (pure supply point), a net demand node (pure demand point), or a neutral transshipment node of a commodity. In this problem, Figure 1, there are six nodes namely node 1 and node 2 are supply nodes (pure supply points), node 3 and node 4 are transshipment nodes, while node 5 and node 6 are demand nodes (pure demand points). There are also eight direct paths connecting a pair of nodes, namely $(1,3),(1,4),(2,3),(2,4),(3,5),(3,6),(4,5)$, and $(4,6)$ (Thompson \& Thore, 1992).

The network model in this problem can be solved by using a form of primal linear programming, to minimize transportation costs (shipping costs) (Khan et al., 2011). Suppose the minimum cost flow in primal linear programming is

$$
\begin{aligned}
& \min \sum c x \\
& \text { s.t. } \sum M x=b
\end{aligned}
$$




$$
x \geq 0,
$$

where $c_{i j}$ is the delivery cost of a unit of flow in the path $i$ to $j$, is notated $(i, j)$, is defined as a column vector $c=\left(c_{13}, c_{14}, c_{23}, c_{24}, c_{35}, c_{36}, c_{45}, c_{46}\right)$. The notation $M$ is a matrix that is assumed that each path is related to the column. In each column, two entries are not equal to zero, namely +1 if the path enters the node, and -1 if the path exits the node, while the other entries in each column are zero. So, we get the $M$ matrix as follows

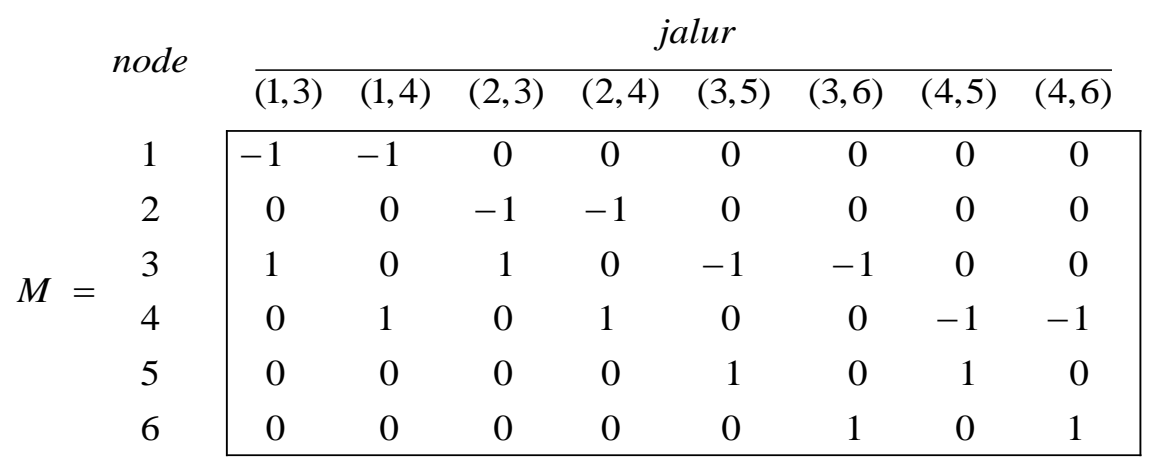

The notation $b$ is a supply and demand commodity. In the above problem, $b$ relates to six nodes, namely supply commodities entering the system at node 1 and node 2 are denoted $b_{1}$ and $b_{2}$ are negative, while demand commodities leaving the system at node 5 and node 6 are denoted $b_{5}$ and $b_{6}$ are positive, so that it can be defined six components of the supply and demand vector columns, i.e.

$$
b=\left(-b_{1},-b_{2}, 0,0, b_{5}, b_{6}\right) \text {. }
$$

The notation $x$ is a vector column, defined $x=\left(x_{13}, x_{14}, x_{23}, x_{24}, x_{35}, x_{36}, x_{45}, x_{46}\right)$, it is assumed that $x_{i j}$ is the amount of capacity distributed (moved) through the path $i$ to $j$.

Primal linear programming in equation (1) can be simplified using a dual program with a dual variable ( $u$ ) not limited by signs, because the primal limitations in equation (1) are similarities. The dual programming of equation (1) is

$$
\begin{aligned}
& \max \sum u b \\
& \text { s.t. } \sum u M \leq c \\
& u \text { not limited by signs. }
\end{aligned}
$$

Based on primal-dual programming above, components can be defined as follows 


\begin{tabular}{l|rrrrrrrrl}
\multicolumn{1}{c}{$x_{13}$} & $x_{14}$ & $x_{23}$ & $x_{24}$ & $x_{35}$ & $x_{36}$ & $x_{45}$ & $x_{46}$ \\
$u_{1}$ & -1 & -1 & 0 & 0 & 0 & 0 & 0 & 0 \\
$u_{2}$ & 0 & 0 & -1 & -1 & 0 & 0 & 0 & 0 & $=-b_{1}$ \\
$u_{3}$ & 1 & 0 & 1 & 0 & -1 & -1 & 0 & 0 & $=b_{2}$ \\
$u_{4}$ & 0 & 1 & 0 & 1 & 0 & 0 & -1 & -1 & $=$ \\
$u_{5}$ & 0 & 0 & 0 & 0 & 1 & 0 & 1 & 0 \\
$u_{6}$ & 0 & 0 & 0 & 0 & 0 & 1 & 0 & 1 & $=b_{5}$ \\
\cline { 2 - 9 } & $c_{13}$ & $c_{14}$ & $c_{23}$ & $c_{24}$ & $c_{35}$ & $c_{36}$ & $c_{45}$ & $c_{46}$
\end{tabular}

In the component above, it can be seen that each column in matrix $M$ has one +1 entry and one entry -1 , while the remainder is 0 , so it is easier to see the boundaries related to the path $i$ to $j$ in the form

$$
-u_{i}+u_{j} \leq c_{i j}
$$

The notation $u_{i}^{*}$ is a dual optimal solution and can be interpreted as cutting the value of the commodity at point $i$, because $u_{i}=u_{i}^{*}+k$ and $u_{j}=u_{j}^{*}+k$, where $k$ is any real number so that from equation (3) can be obtained

$$
-\left(u_{i}^{*}+k\right)+\left(u_{j}^{*}+k\right)=-u_{i}^{*}+u_{j}^{*} \leq c_{i j} .
$$

where $k$ excludes each other (Thompson \& Thore, 1992).

Based on equation (4), cutting the value of the commodity along path $i$ to $j$ cannot exceed the unit cost of $c_{i j}$, so the problem in the dual program of equations (2) and (4) can be made as optimum points as follows

$$
\begin{array}{ll}
-u_{1}^{*}+u_{3}^{*} \leq c_{13}, & x_{13}^{*}\left(c_{13}+u_{1}^{*}-u_{3}^{*}\right)=0 \\
-u_{1}^{*}+u_{4}^{*} \leq c_{14}, & x_{14}^{*}\left(c_{14}+u_{1}^{*}-u_{4}^{*}\right)=0 \\
-u_{2}^{*}+u_{3}^{*} \leq c_{23}, & x_{23}^{*}\left(c_{23}+u_{2}^{*}-u_{3}^{*}\right)=0 \\
-u_{2}^{*}+u_{4}^{*} \leq c_{24}, & x_{24}^{*}\left(c_{24}+u_{2}^{*}-u_{4}^{*}\right)=0 \\
-u_{3}^{*}+u_{5}^{*} \leq c_{35}, & x_{35}^{*}\left(c_{35}+u_{3}^{*}-u_{5}^{*}\right)=0 \\
-u_{3}^{*}+u_{6}^{*} \leq c_{36}, & x_{36}^{*}\left(c_{36}+u_{3}^{*}-u_{6}^{*}\right)=0 \\
-u_{4}^{*}+u_{5}^{*} \leq c_{45}, & x_{45}^{*}\left(c_{45}+u_{4}^{*}-u_{5}^{*}\right)=0 \\
-u_{4}^{*}+u_{6}^{*} \leq c_{46}, & x_{46}^{*}\left(c_{46}+u_{4}^{*}-u_{6}^{*}\right)=0
\end{array}
$$

Based on the optimum point above, we can get the value of $u_{i}$ and $x_{i j}$ so that we will get a minimum transportation cost (shipping cost), i.e.

$$
\text { total cost }=\sum\left[x_{i j} \cdot\left(u_{\text {final }}-u_{\text {initial }}\right)\right]
$$

The solution to this problem uses linear programming called POM (Loganathan \& Lakshmi, 2015).

\section{Numerical Illustration Analysis}

For example, in the case of oil production, it is known that supply commodities are $b_{1}=150$ and $b_{2}=200$, and demand commodities are $b_{5}=175$ and $b_{6}=175$. How the corresponding equation form, as in the equation (1), then will be shown that each equation is the sum of the number of currents flowing 
into each node is equal to the sum of the number of currents flowing out of each node. From equation (1), it is obtained

$$
M x=b
$$

Because $b_{1}$ and $b_{2}$ are supply commodities, they are negative because the current flows into the system of each node, while $b_{5}$ and $b_{6}$ are demand commodities, it is positive because the current flows out of the system from each node. So, the corresponding equation is

$$
M x=b=-b_{1}-b_{2}+b_{5}+b_{6} .
$$

It is assumed that $e$ consists of $n$ components of row vectors which are all valued at 1 , where $n$ is the number of nodes, denoted as follows

$$
e=\left[\begin{array}{lll}
1 & \cdots & 1
\end{array}\right]
$$

and also known from section 2, $M$ is a defined matrix, as follows

$$
M=\begin{array}{rrrrrrrr|}
-1 & -1 & 0 & 0 & 0 & 0 & 0 & 0 \\
0 & 0 & -1 & -1 & 0 & 0 & 0 & 0 \\
1 & 0 & 1 & 0 & -1 & -1 & 0 & 0 \\
0 & 1 & 0 & 1 & 0 & 0 & -1 & -1 \\
0 & 0 & 0 & 0 & 1 & 0 & 1 & 0 \\
0 & 0 & 0 & 0 & 0 & 1 & 0 & 1 \\
\hline
\end{array}
$$

Based on the matrix definition it can be seen that there are six nodes, so that

$$
\begin{aligned}
& e M=\left[\begin{array}{llllll}
1 & 1 & 1 & 1 & 1 & 1
\end{array}\right]\left[\begin{array}{rrrrrrrr|}
-1 & -1 & 0 & 0 & 0 & 0 & 0 & 0 \\
0 & 0 & -1 & -1 & 0 & 0 & 0 & 0 \\
1 & 0 & 1 & 0 & -1 & -1 & 0 & 0 \\
0 & 1 & 0 & 1 & 0 & 0 & -1 & -1 \\
0 & 0 & 0 & 0 & 1 & 0 & 1 & 0 \\
0 & 0 & 0 & 0 & 0 & 1 & 0 & 1 \\
\hline
\end{array}\right. \\
& e M=\left[\begin{array}{llllll}
0 & 0 & 0 & 0 & 0 & 0
\end{array}\right]=0 .
\end{aligned}
$$

Then, if equation (1) is multiplied by e on the left and right sides, it will be obtained

$$
e M x=e b \text {, }
$$

because $e M=0$ then $e M x=0$, and certainly $e b=0$ so $b=0$, from equation (6) obtained

so that

$$
M x=b=-b_{1}-b_{2}+b_{5}+b_{6} \text {, }
$$

that means

$$
0=-b_{1}-b_{2}+b_{5}+b_{6}
$$

$$
b_{1}+b_{2}=b_{5}+b_{6} \Rightarrow 150+200=175+175=350 \text {. }
$$

So, it is evident that each equation states that the sum of the number of currents flowing into each node, equals the sum of the number of currents flowing out of each node.

\section{Conclussion}

In this paper, a theoretical study of the distribution network of oil production has been carried out. Based on the discussion on numerical illustrations, it can be shown that the total inventory count (number of nodes entered) equals the total number of requests (number of nodes exiting). This event is called the 
balanced transportation model, but it does not rule out the possibility because some factors the total inventory amount (the number of incoming nodes) is greater than the total demand (the number of outgoing nodes) can occur.

\section{References}

Antunes, C. H. \& Gomes, Á. (2008). Operational research models and methods in the energy sector. European Journal of Operational Research. doi: 10.1016/j.ejor.2008.03.013

Boo, C. J., Kim, J. H., Kim, H. C., Kang, M. J. \& Lee, K. Y. (2013). Energy Efficient Temperature Control for Peak Power Reduction in Building Cooling Systems. International Journal of Control and Automation, 6(6), pp. 105-114.

Dragićević, S. \& Bojić, M. (2009). Application of Linear Programming in Energy Management. Serbian Journal of Management, 4(2), pp. 227-238.

Dragićević, S. M. \& Bojić, M. Lj. (2010). Optimization of Industrial Energy Supply System. FME Transactions, 38(2), pp.87-94.

Ezema, B. I. \& Amakom, U. (2012). Optimizing Profit with the Linear Programming Model: A Focus on Golden Plastic Industry Limited, Enugu, Nigeria. Interdisciplinary Journal of Research in Business, 2(2), pp. 37-49.

Iheagwara, A. I., Opara, J., Esemokumo, P. A. \& Lebechim J. I. (2014). Application of Linear Programming Problem on Niger Mills Company PLC Calabar. International Journal of Innovation and Research in Educational Sciences, 1(2), pp. 105-114.

Khan, I. U., Bajuri, N. H. \& Jadoon, I. A. (2011). Optimal Production Planning for Ici Pakistan Using Linear Programming and Sensitivity Analysis. International Journal of Business and Social Science, 2(23), pp. 206212.

Loganathan, N. \& Lakshmi, K. (2015). Demand Side Energy Management for Linear Programming Method. TELKOMNIKA Indonesian Journal of Electrical Engineering, 14(1), pp. 72-79.

Thompson, G. L. \& Thore, S. (1992). Computational Economic. San Francisco: Scientific Press.

Turkay, B. (1998). Distribution System Planning Using Mixed Integer Programming. ELEKTRIK, 6(1), pp. 37-48. 